\title{
Altered auditory processing and effective connectivity in 22q11.2 deletion syndrome
}

Larsen, Kit Melissa; Mørup, Morten; Birknow, Michelle Rosgaard; Fischer, Elvira; Hulme, Oliver; Vangkilde, Anders; Schmock, Henriette; Baaré, William Frans Christiaan; Didriksen, Michael; Olsen, Line Total number of authors:

13

Published in:

Schizophrenia Research

Link to article, DOI:

10.1016/j.schres.2018.01.026

Publication date:

2018

Document Version

Peer reviewed version

Link back to DTU Orbit

Citation (APA):

Larsen, K. M., Mørup, M., Birknow, M. R., Fischer, E., Hulme, O., Vangkilde, A., Schmock, H., Baaré, W. F. C., Didriksen, M., Olsen, L., Werge, T., Siebner, H. R., \& Garrido, M. I. (2018). Altered auditory processing and effective connectivity in 22q11.2 deletion syndrome. Schizophrenia Research.

https://doi.org/10.1016/j.schres.2018.01.026

\section{General rights}

Copyright and moral rights for the publications made accessible in the public portal are retained by the authors and/or other copyright owners and it is a condition of accessing publications that users recognise and abide by the legal requirements associated with these rights.

- Users may download and print one copy of any publication from the public portal for the purpose of private study or research.

- You may not further distribute the material or use it for any profit-making activity or commercial gain

- You may freely distribute the URL identifying the publication in the public portal 


\title{
Altered auditory processing and effective connectivity in 22q11.2 deletion syndrome
}

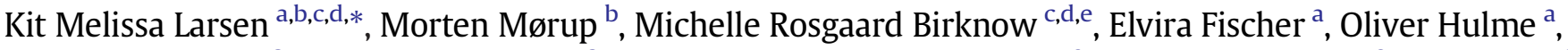 \\ Anders Vangkilde ${ }^{c}$, Henriette Schmock ${ }^{c}$, William Frans Christiaan Baaré ${ }^{\mathrm{a}}$, Michael Didriksen ${ }^{\mathrm{e}}$, Line Olsen ${ }^{\mathrm{c}, \mathrm{d}}$, \\ Thomas Werge e,d,f, Hartwig R. Siebner ${ }^{\mathrm{a}, \mathrm{f}, \mathrm{g}}$, Marta I. Garrido ${ }^{\mathrm{h}, \mathrm{i}, \mathrm{j}, \mathrm{k}}$
}

\footnotetext{
a Danish Research Centre for Magnetic Resonance, Centre for Functional and Diagnostic Imaging and Research, Copenhagen University Hospital Hvidovre, Denmark

${ }^{\mathrm{b}}$ DTU Compute, Cognitive Systems, Technical University of Denmark, Denmark

c Institute of Biological Psychiatry, Mental Health Centre Sct. Hans, Copenhagen University Hospital, Roskilde, Denmark

d $i P S Y C H$, The Lundbeck Foundation Initiative for Integrative Psychiatric Research, Denmark

e Synaptic Transmission, H. Lundbeck A/S, Valby, Denmark

${ }^{\mathrm{f}}$ Department of Clinical Medicine, Faculty of Health and Medical Sciences, University of Copenhagen, Denmark

${ }^{g}$ Department of Neurology, Copenhagen University Hospital Bispebjerg, Copenhagen, Denmark

h Queensland Brain Institute, The University of Queensland, Brisbane, Australia

i Centre for Advanced Imaging, The University of Queensland, Brisbane, Australia

${ }^{j}$ Australian Research Council Centre of Excellence for Integrative Brain, The University of Queensland, Brisbane, Australia

${ }^{\mathrm{k}}$ School of Mathematics and Physics, The University of Queensland, Brisbane, Australia
}

\section{A R T I C L E I N F O}

\section{Article history:}

Received 14 September 2017

Received in revised form 4 December 2017

Accepted 21 January 2018

Available online $\mathrm{xxxx}$

\section{Keywords:}

22q11 deletion syndrome

Dynamic causal modelling

EEG

Mismatch negativity

N1 component

\begin{abstract}
A B S T R A C T
22q11.2 deletion syndrome (22q11.2DS) is one of the most common copy number variants and confers a markedly increased risk for schizophrenia. As such, 22q11.2DS is a homogeneous genetic liability model which enables studies to delineate functional abnormalities that may precede disease onset. Mismatch negativity (MMN), a brain marker of change detection, is reduced in people with schizophrenia compared to healthy controls. Using dynamic causal modelling (DCM), previous studies showed that top-down effective connectivity linking the frontal and temporal cortex is reduced in schizophrenia relative to healthy controls in MMN tasks. In the search for early risk-markers for schizophrenia we investigated the neural basis of change detection in a group with 22q11.2DS. We recorded high-density EEG from 19 young nonpsychotic 22q11.2 deletion carriers, as well as from 27 healthy non-carriers with comparable age distribution and sex ratio, while they listened to a sequence of sounds arranged in a roving oddball paradigm. Despite finding no significant reduction in the MMN responses, whole-scalp spatiotemporal analysis of responses to the tones revealed a greater fronto-temporal N1 component in the 22q11.2 deletion carriers. DCM showed reduced intrinsic connection within right primary auditory cortex as well as in the topdown, connection from the right inferior frontal gyrus to right superior temporal gyrus for 22q11.2 deletion carriers although not surviving correction for multiple comparison. We discuss these findings in terms of reduced adaptation and a general increased sensitivity to tones in 22q11.2DS.
\end{abstract}

(C) 2018 Elsevier B.V. All rights reserved.

\section{Introduction}

The 22q11.2 deletion is one of the most common copy number variants (CNV) with a prevalence of 1:2000 to 1:4000 (Goodship et al., 1998; Oskarsdóttir et al., 2004; Shprintzen, 2005). The 22q11.2 deletion syndrome (22q11.2DS) is characterized by multiple somatic disorders, cognitive deficits and learning disabilities (Karayiorgou et al., 2010;

Abbreviations: DCM, dynamic causal modelling; MMN, mismatch negativity; 22q11.2DS, 22q11.2 deletion syndrome.

* Corresponding author.

E-mail address: m.larsen@uq.edu.au (K.M. Larsen).
Robin and Shprintzen, 2005). Further, the syndrome is associated with hearing loss (Jiramongkolchai et al., 2016). Recent studies have shown that people carrying the deletion are at higher risk for several neurodevelopmental disorders including autism, ADHD, and schizophrenia, (Bassett et al., 2008; Karayiorgou et al., 2010; Purcell et al., 2009; Schneider et al., 2014; Stefansson et al., 2008). Clinical observation studies have shown that approximately $25 \%$ of the carriers meet diagnostic criteria for schizophrenia by adulthood (Schneider et al., 2014) and with odds ratios above 16, the deletion is one of the largest known risk factors for schizophrenia (Marshall et al., 2016; Szatkiewicz et al., 2014). In addition, results from a new nationwide Danish study showed that people diagnosed with 22q11.2DS had six to eight times higher risk 
of developing schizophrenia spectrum disorders as compared to the general population (Hoeffding et al., 2017; Vangkilde et al., 2016b). For this reason, investigating the neurobiology of 22q11.2 deletion carriers can provide important insights into the pathogenesis of schizophrenia and potential disease risk markers.

It is well established that people with schizophrenia show a reduced mismatch negativity (MMN) at fronto-central electrodes over the scalp when assessed with electroencephalography (EEG) (Catts et al., 1995; Michie, 2001; Näätänen and Kähkönen, 2009; Umbricht and Krljesb, 2005). MMN is evoked in oddball paradigms, whereby standard stimuli form a rule that is occasionally violated by oddball events. Defined as the negative deflection in the event-related potential peaking around $100-250 \mathrm{~ms}$ after the change onset, the MMN emerges when subtracting the response to a standard tone from the response to a deviant tone (Näätänen, 1995; Näätänen et al., 2007). MMN is not only reduced in chronic schizophrenia but also in first episode psychosis, (Atkinson et al., 2012; Hsieh et al., 2012), first degree relatives (Jessen et al., 2001; Michie et al., 2002) and further shown to be a promising biomarker for psychosis prediction (Bodatsch et al., 2015), see also (Randeniya et al., 2017) for a review on MMN in the continuum of psychosis. Only a limited number of studies have investigated MMN in 22q11.2 deletion carriers (Baker et al., 2005; Zarchi et al., 2013). Baker and colleagues (Baker et al., 2005) found reduced duration MMN consistent with findings in the schizophrenia literature (Baldeweg et al., 2002). In contrast, Zarchi et al. (2013) failed to replicate this finding but found that Gap-MMN amplitudes in the 22q11.2DS group predicted the negative symptoms scores (from the Positive and Negative Syndrome Scale, PANSS) where smaller MMN amplitudes were associated with higher scores of the PANSS. Notably, the disease states of the 22q11.2DS groups in the two mentioned studies deviate from each other. In (Baker et al., 2005) no participants met criteria for a diagnosis of psychotic disorder, whereas in (Zarchi et al., 2013) a proportion of the participants (14.63\%) were diagnosed with psychotic disorders and three of these met the DSM-IV-TR for schizophrenia.

Approaches to modelling MMN using Dynamic Causal Modelling (DCM) have viewed the underlying mechanism of MMN in terms of the predictive coding hypothesis (Garrido et al., 2008; Rao and Ballard, 1999). In this way, MMN is caused by an interplay between current inputs and predictions based on a learnt regularity (Garrido et al., 2009a). The network implementation of these processes involve bottom-up and top-down connections that link lower- with higher-level sensory areas (Friston, 2003). This interplay appears to be disrupted in schizophrenia (Adams et al., 2013; Dima et al., 2012, 2010; Fogelson et al., 2014) as well as in unaffected relatives (Ranlund et al., 2016) especially in top-down processing, i.e., connections from higher to lower order areas. Since functional disintegration among brain regions phrased as "The disconnection hypothesis" is believed to be one of the core pathologies of psychosis (Friston, 1998), we use DCM in addition to conventional MMN analysis in sensor space, to test this notion of disconnectivity in the 22q11DS population.

In this study, the neuronal connectivity underlying change detection was assessed in a group of young non-psychotic 22q11.2 deletion carriers as well as in a healthy age- and sex-comparable control group using DCM. Given that schizophrenia patients show reduced MMN responses, and that 22q11.2DS are a schizophrenia high-risk group, we hypothesized that the 22q11.2 deletion carriers would also express a reduction in MMN responses. Based on previous identified neural generators of MMN, we formulated families of DCMs according to their type of connections, to test the hypothesis that 22q11.2 deletion carriers would afford reduced top-down connectivity within the network accounting for MMN, compared to healthy non-carriers. Finally, we explored whether effective connectivity in 22q11.2 deletion carriers as well as MMN amplitudes were associated with the individual symptoms score in the 22q11.2 deletion carriers.

\section{Materials and methods}

\subsection{Participants}

We included 1922q11.2 deletion carriers without a current or previous history of schizophrenia. All carriers had a verified deletion within the $3 \mathrm{Mb}$ region at chromosome 22q11.2. Our control group included 27 healthy individuals without the 22q11.2 deletion. Groups were comparable with respect to sex ratio (male/female controls: 18/9, carriers: $13 / 6, \chi^{2}=0.02, p=0.90$ ) and age distribution (controls age range: $12-25$ years; mean age: 15.96 , standard deviation $(S D)=2.71$ years; 22q11.2 age range $12-21$ years; mean age: 15.47, SD 2.41 years, $\mathrm{t}_{44}=-0.63 p=0.53$ ).

All participants were evaluated for the presence of current psychiatric disorders and intelligence level as previously described (Vangkilde et al., 2016a). One of the 22q11.2 deletion carriers was taking $20 \mathrm{mg}$ of retalin. Apart from this, no other participant took medication acting on the central nervous system. The Structured Interview for Prodromal Symptoms (SIPS) (McGlashan et al., 2012; Miller et al., 2003) was used to evaluate the presence of schizophrenia-related symptoms within four domains: positive, negative, disorganized and general symptoms. All clinical interviews were conducted by two experienced and certified clinicians. None of the participants had psychosis but the 22q11.2DS group had significantly elevated SIPS scores for all four SIPS symptom domains relative to the control group. Further, the 22q11.2Ds were presented with lower IQ than the controls, see Table 1 for a summary of clinical and demographic data as well as description of IQ.

The following exclusion criteria were applied to controls: a) schizophrenia, schizotypal and delusional disorders (ICD10 DF20-29); b) bipolar disorder (ICD10 DF30-31); c) depression (ICD DF32-33) except for a past episode of mild or moderate depression (ICD10 DF 32.0 or 32.1 ); d) substance abuse; or e) a first degree relative with a psychotic illness.

This study was approved by the Regional Ethical Committee of Copenhagen (project id: H-3-2012-136) and the Danish Data protection Agency (project id: 2007-58-0015). All participants underwent a verbal and written informed consent process. Participants under the age of 18 provided a verbal assent while their parents completed a written consent. This study is part of a larger Danish nationwide study and an extensive description of the recruitment of participants is described in (Schmock et al., 2015).

\subsection{Stimuli}

Participants were presented with an auditory roving mismatch negativity paradigm adapted from (Garrido et al., 2008), see Fig. 1 for details of stimuli as well as Supplementary material. Prior to the experiment, audiometric testing was performed to confirm that participants were able to hear the tones used for eliciting the event related potentials (20 dB random test Oscilla USB-310 Tablet screening audiometer, Aarhus, Denmark). At $1000 \mathrm{~Hz}$ the observed threshold levels were $($ mean $=20.1 \mathrm{~dB}, \mathrm{SD}=0.5)$ for controls and (mean $=23.4 \mathrm{~dB}$, $\mathrm{SD}=4.0)$ for $22 \mathrm{q} 11.2$.

\subsection{Data acquisition and pre-processing}

EEG data were recorded using a 128 channel ActiveTwo Biosemi System (BioSemi, Amsterdam, Netherlands) at a sampling frequency of $4096 \mathrm{~Hz}$. Pre-processing was carried out using EEGLAB (Delorme and Makeig, 2004), which included referencing to the nose, bandpass filtering between $0.5 \mathrm{~Hz}-40 \mathrm{~Hz}$ using a second order Butterworth filter, downsampling to $500 \mathrm{~Hz}$, and finally epoching with a peristimulus window of $-100 \mathrm{~ms}$ to $400 \mathrm{~ms}$. The epochs were baseline corrected using the average over the time window $-100 \mathrm{~ms}$ to $-10 \mathrm{~ms}$. The epoched data were then exported to SPM12b where the artefact removals, mass-univariate spatiotemporal analysis as well as the DCM analysis 
Table 1

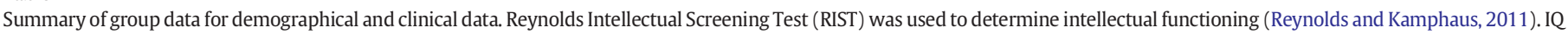

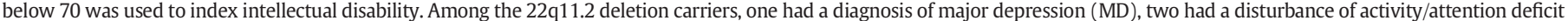
disorder without hyperactivity (ADHD/ADD), and seven had a diagnosis of anxiety or phobia and one with both autism spectrum disorder (ASD) and phobia.

\begin{tabular}{|c|c|c|c|}
\hline Measures & Control group & 22q11.2 group & Group statistics \\
\hline $\begin{array}{l}\text { Age } \\
\text { Sex } \\
\text { IQ }\end{array}$ & $\begin{array}{l}\text { Mean } 15.96 \mathrm{SD}=2.71 \\
18 \text { males } / 9 \text { females } \\
\text { Median }=108.0 \\
\text { 90th percentile }=127.0 \\
\text { 10th percentile }=95.2 \\
\text { Mean } 109.0 \mathrm{SD}=12.5\end{array}$ & $\begin{array}{l}\text { Mean } 15.47 \mathrm{SD}=2.41 \\
13 \text { males } / 6 \text { females } \\
\text { Median }=82.0 \\
\text { 90th percentile }=94.4 \\
\text { 10th percentile }=63.8 \\
\text { Mean } 77.7 \mathrm{SD}=16.06\end{array}$ & $\begin{array}{l}\mathrm{t}_{44}=-0.63, p=0.53 \\
\mathrm{X}^{2}=0.02, p=0.90 \\
\mathrm{t}_{44}=-7.01, p<0.001\end{array}$ \\
\hline \multicolumn{4}{|l|}{ SIPS - subscales } \\
\hline Negative & $\begin{array}{l}\text { Mean } 0.59 \mathrm{SD}=1.04 \\
\text { Range } 0-4\end{array}$ & $\begin{array}{l}\text { Mean } 6.68 \text { SD }=3.67 \\
\text { Range } 1-16\end{array}$ & $\mathrm{~W}=477, p \leq 0.001$ \\
\hline Positive & $\begin{array}{l}\text { Mean } 0.81 \mathrm{SD}=1.49 \\
\text { Range 0-6 }\end{array}$ & $\begin{array}{l}\text { Mean } 2.74 \text { SD }=3.07 \\
\text { Range 0-12 }\end{array}$ & $\mathrm{W}=305.5, p=0.008$ \\
\hline Disorganized & $\begin{array}{l}\text { Mean } 0.11 \mathrm{SD}=0.42 \\
\text { Range } 0-2\end{array}$ & $\begin{array}{l}\text { Mean } 1.68 \mathrm{SD}=1.83 \\
\text { Range } 0-6\end{array}$ & $\mathrm{~W}=404, \mathrm{p}<0.001$ \\
\hline Generalized & $\begin{array}{l}\text { Mean } 0.15 \mathrm{SD}=0.46 \\
\text { Range } 0-2\end{array}$ & $\begin{array}{l}\text { Mean } 0.95 \mathrm{SD}=1.90 \\
\text { Range } 0-7\end{array}$ & $\mathrm{~W}=312.5, p=0.027$ \\
\hline \multicolumn{4}{|l|}{ Diagnosis } \\
\hline $\begin{array}{l}\text { MD } \\
\text { ADHD/ADD } \\
\text { Anxiety or phobia } \\
\text { ASD }\end{array}$ & $\begin{array}{l}N=0 \\
N=0 \\
N=0 \\
N=0\end{array}$ & $\begin{array}{l}N=1 \\
N=2 \\
N=8 \\
N=1\end{array}$ & \\
\hline
\end{tabular}

were performed (http://www.fil.ion.ucl.ac.uk/spm/). The artefact removal was performed using a simple threshold approach, where epochs were rejected if their values exceeded $\pm 100 \mu \mathrm{V}$. One of the participants (belonging to the 22q11.2 group) was discarded because the majority of epochs were rejected with this approach (above 80\%).

Trials were sorted according to their tone repetition number and collapsed across the two frequencies (i.e. frequencies $1000 \mathrm{~Hz}$ and 1200 $\mathrm{Hz}$ ). Responses to the standards were subtracted from the response to the deviant (D), for the first standard (S1) up until the fifth standard (S5). We did this in order to estimate which standard tone would produce the largest MMN response in the pooled sample (i.e., averaged over both the carrier and control groups). This tone was then used as the standard tone for further analysis. We stopped at S5 since S6 to S8 had fewer than 100 trials and we wanted to guarantee a good signal to noise ratio comparable to that afforded by S1 to S5.

To enable spatio-temporal analysis in sensor space, the epoched EEG data were converted into scalp-map images of dimension $64 \times 64$. These were obtained using interpolation followed by smoothing using a Gaussian kernel specified by a FWHM of $8 \mathrm{~mm}^{2}$ in the spatial dimen-

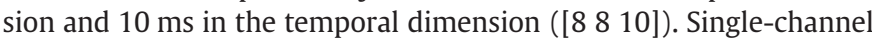
MMN responses were extracted from the Fz channel given a priori knowledge that the MMN response is greater over fronto-central areas, (Näätänen et al., 2007). For the DCM, data were re-referenced to the average over sensors to ensure proper source reconstruction.

\subsection{Dynamic causal modelling}

We used DCM to investigate the neural networks underlying MMN generation and test the hypothesis that 22q11 deletion carriers would express reduced top-down connectivity. DCM is a hypothesis driven method that estimates effective connectivity between specified brain areas and how this is affected by experimental factors, where effective connectivity is the influence one brain area exerts over another (David et al., 2006; Friston et al., 2003). Critically, DCM is able to infer the directionality of the interactions between brain regions. For a more thorough explanation of DCM, see supplementary material.

The network architecture of the roving MMN paradigm has been studied previously in healthy individuals (Boly et al., 2011; Garrido et al., 2007, 2008, 2009b) using DCM, with the proposed models being motivated by previous fMRI and EEG work on MMN generators (Doeller et al., 2003; Grau et al., 2007; Opitz et al., 2002; Rinne et al., 2000). According to these studies, MMN generation engages bilateral sources in the primary auditory cortex (A1) superior temporal gyrus

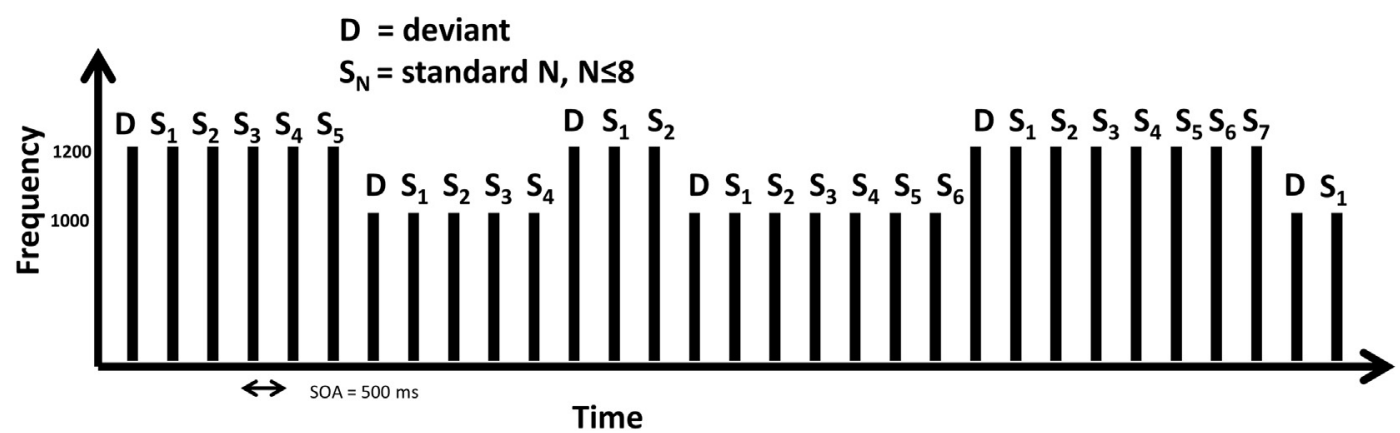

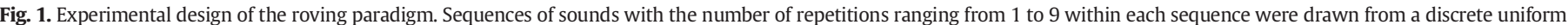

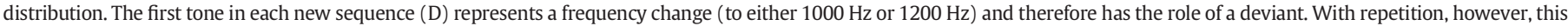

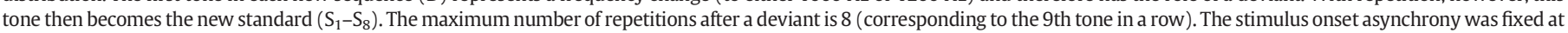
$500 \mathrm{~ms}$. 
(STG) and inferior frontal gyrus (IFG), with the IFG usually being most consistent in the right side.

Although the functional anatomy of MMN generation has been widely studied in healthy people it remains unknown in the 22q11.2 deletion carriers. In order to explore the network structure we defined 16 models starting with a parsimonious model comprising of bilateral A1 and STG with only forward connections. The remaining models where then built by adding hierarchical levels with increasing complexity until we had a full network with six sources: bilateral A1, STG and IFG (see Fig. 2). Forward (F) and backward (B) connections were added at all levels of the hierarchy as well as lateral connections linking left and right STG. The models where divided into families according to the type of connections present in each family Fig. 2.

\subsection{Statistical analysis}

We used two sample $t$-test and Wilcoxon rank sum test to test for carrier-control differences in IQ and SIPS scores, respectively.

\subsubsection{Mismatch negativity responses}

The peak for the extracted MMN waveforms was detected on the grand average difference waveform for the pooled data (22q11.2 carriers and controls). This peak was then used to extract individual MMN mean amplitude values ( $\pm 30 \mathrm{~ms}$ around the peak) for each individual participant. Group differences in the MMN responses were assessed using a one-way ANCOVA with group as a factor (22q11.2 deletion carriers and controls) and age and sex as covariates. $p$-values are reported significant if below 0.05 .

\subsubsection{Spatio-temporal maps in sensor space}

Spatio-temporal analysis was performed over the whole sensorspace (i.e. all electrodes) and time ( $-100 \mathrm{~ms}$ to $400 \mathrm{~ms}$ ) using a full factorial $2 \times 2$ design with factors group (controls and 22q11.2DS) and condition (standard and deviant). Further, age and sex were included as covariates. With this approach we could do an unbiased assumption-free search for differences (main effects and interactions) over the entire sensor-time volume and use random field theory to correct for multiple comparison testing (Kilner and Friston, 2010). All $p$-values reported are thresholded using alpha $=0.05$ FWE corrected at cluster level.

\subsection{3. $D C M$}

Each of the 16 DCM models was fitted to each participant individually with the standard and deviant responses in the same model. The between trial effect was set to [0 1], such that the standard response is modelled as the baseline. In this way, DCM estimates the connectivity changes that are necessary to fit the deviant responses. In all models, all connections were allowed to be modulated.

Bayesian model comparison was performed in the pooled data (carriers and controls) comparing the four families using random effects (Penny et al., 2010) to allow for different cognitive strategies and brain networks. Within the winning family, inference on the parameter level was performed using Bayesian model averaging (BMA) (Penny et al., 2010).

Group differences in the parameters were assessed using a one-way ANCOVA with group as a factor (22q11.2 deletion carriers and controls) and age and sex as covariates.
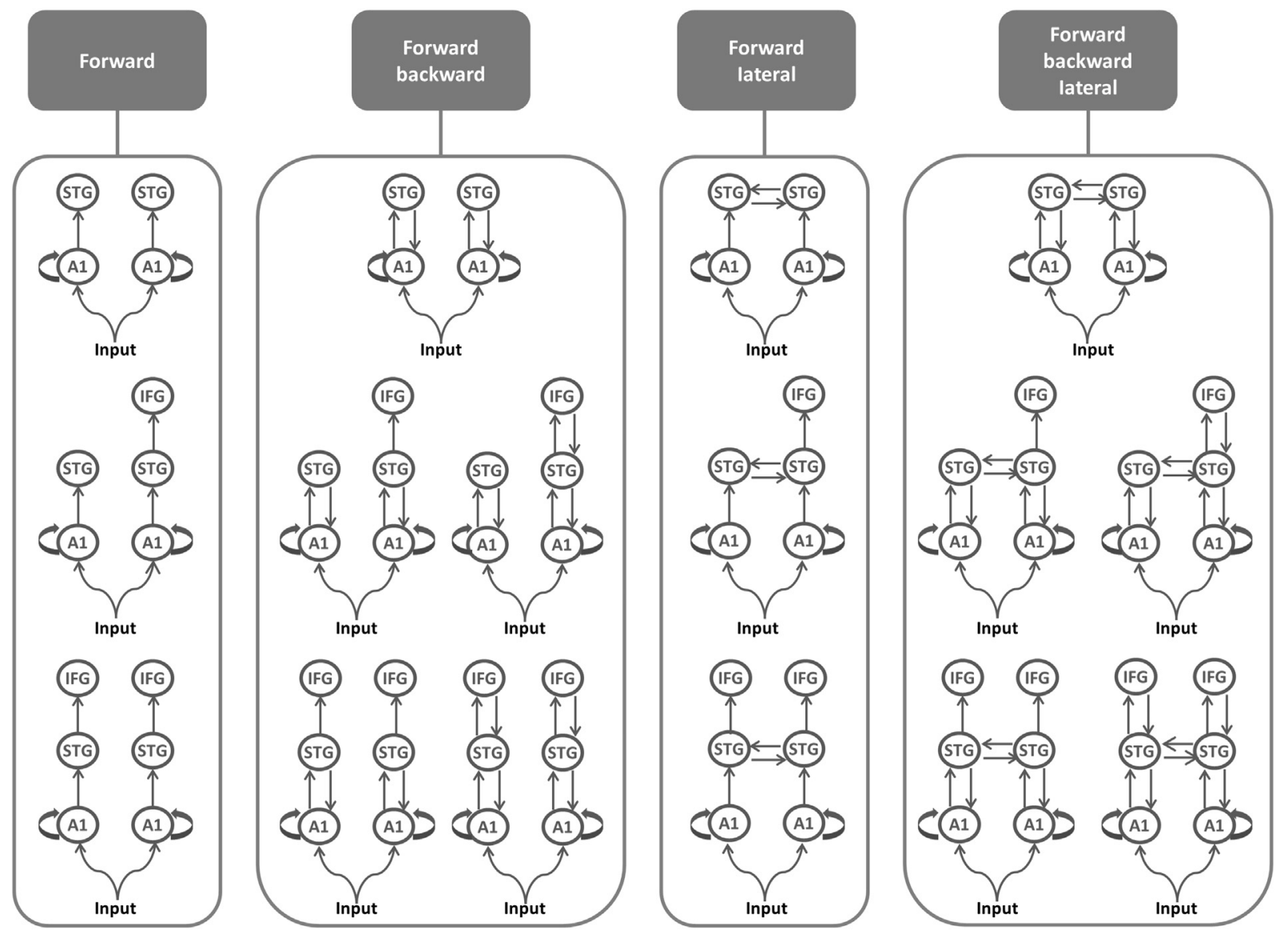

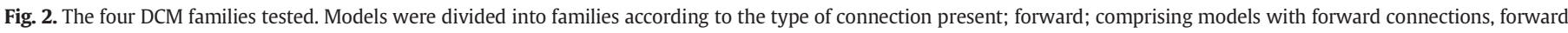

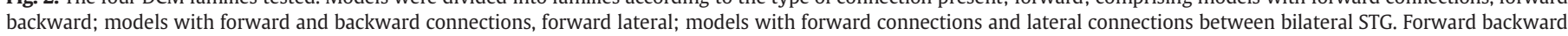
lateral; models with forward and backward connections and lateral connections between bilateral STG. 


\subsubsection{Correlation with clinical symptoms}

Further, we explored if the MMN amplitudes as well as connectivity parameters correlated with the expression of individual symptoms. These post-hoc analyses are reported in the supplementary material.

\subsubsection{Post-hoc correlations and tests}

Since 22q11.2DS is associated with hearing loss (Jiramongkolchai et al., 2016) as well as lower levels of IQ (Vorstman et al., 2015), we post-hoc correlated the results obtained on sensor level (single channel MMN as well as spatio-temporal) and the connectivity parameters from the DCM analysis with hearing thresholds obtained at $1000 \mathrm{~Hz}$ as well as IQ scores within the 22q11.2 group. See supplementary material for further detail. Since a proportion of the $22 \mathrm{q} 11.2$ deletion carriers were presented with a diagnosis of either major depression (1), ADHD/ADD (2), anxiety or phobia (8) or autism spectrum disorder (ASD) (1) (see Table 1), we performed a post hoc test to assess a potential effect of diagnosis by adding it as a covariate in the SPM analysis. In the DCM analysis we performed a split between the 22q11.2 deletion carriers having a diagnosis and those without to post-hoc test for differences in the connections between 22 q11.2 deletion carriers with a presence of a diagnosis and those without.

\section{Results}

\subsection{Mismatch negativity responses}

Fig. 3 shows the grand average data for the conventional MMN analysis for a selected channel (Fz, Fig. 3 A-E) and the whole scalp (Fig. 3F). The third standard tone, $\mathrm{S} 3$, yields the largest MMN in the pooled sample (Fig. 3A), hence we used it as the standard for all subsequent analysis. The mean MMN amplitude as a function of tone repetition followed the shape of a parabola, indicating that surprise builds up until S3, after which it decreases, possibly because a change starts to be expected. Differences in mean MMN amplitudes between 22q11.2 and controls failed to reach significance $\left(F_{1,41}=0.584, p=0.449\right.$, see Fig. $\left.3 \mathrm{E}\right)$, contrary to our initial hypothesis. However, the N1 components for both the responses to the standards and the deviants were enhanced in the carriers compared to the controls (compare Fig. $3 \mathrm{C}$ and D). No effect of the covariates sex $\left(F_{1,41}=0.005, p=0.946\right)$ or age $\left(F_{1,41}=1.480, p=\right.$ 0.231 ) was observed.

\subsection{Spatio-temporal maps in sensor space}

Statistical parametric mapping revealed a significant main effect of group (Fig. 4) peaking at $90 \mathrm{~ms}\left(\mathrm{~F}_{1,84}=20.21, p=0.001\right.$, FWE corrected

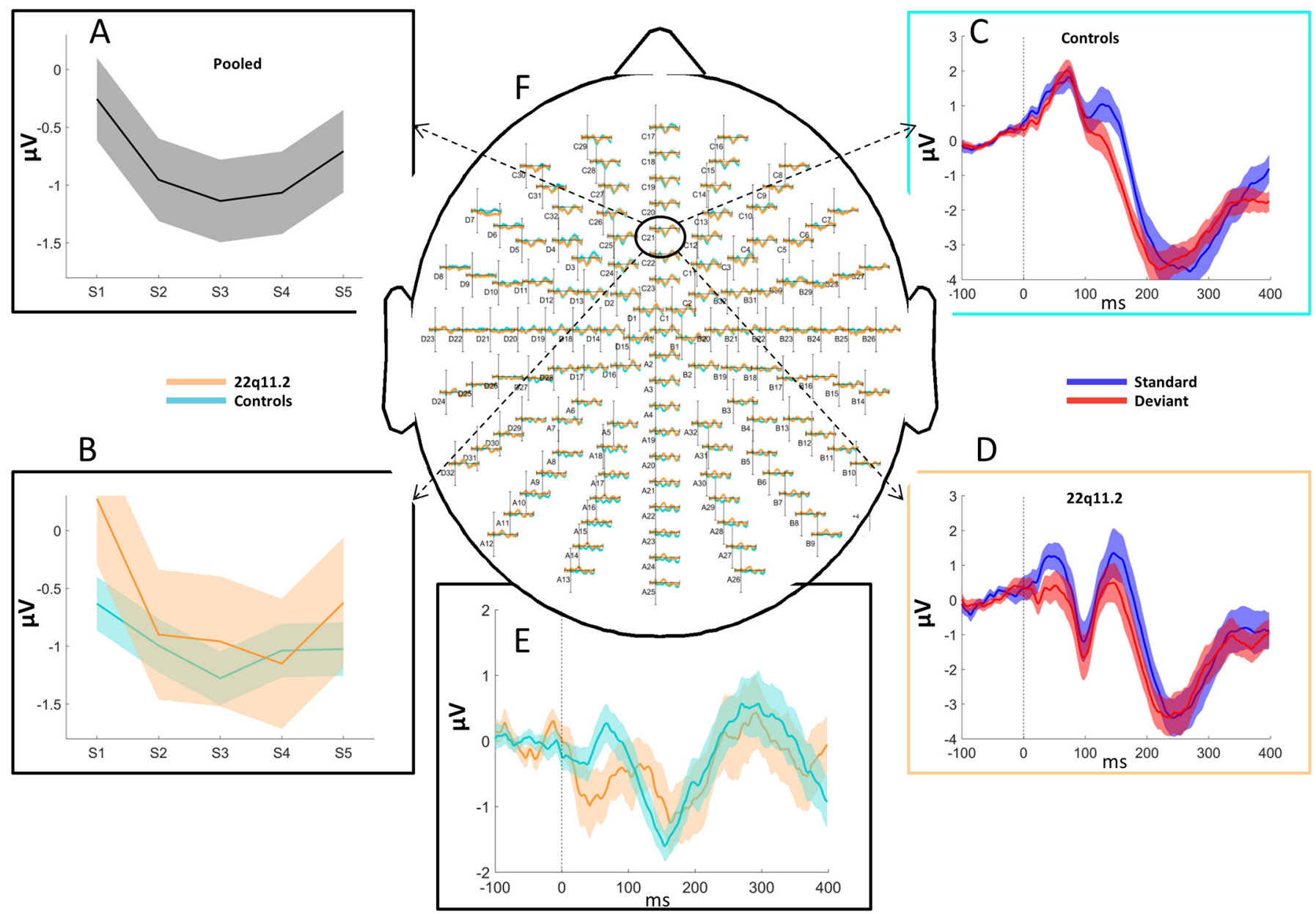

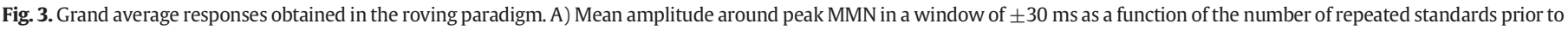

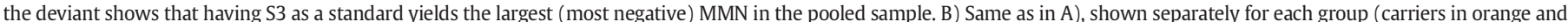

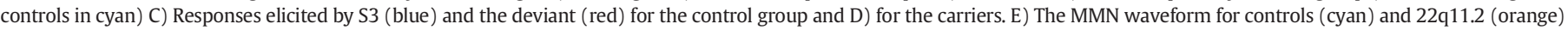

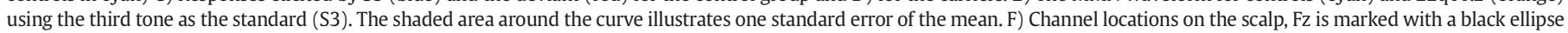
and is used for all subfigures. (For interpretation of the references to color in this figure legend, the reader is referred to the web version of this article.) 


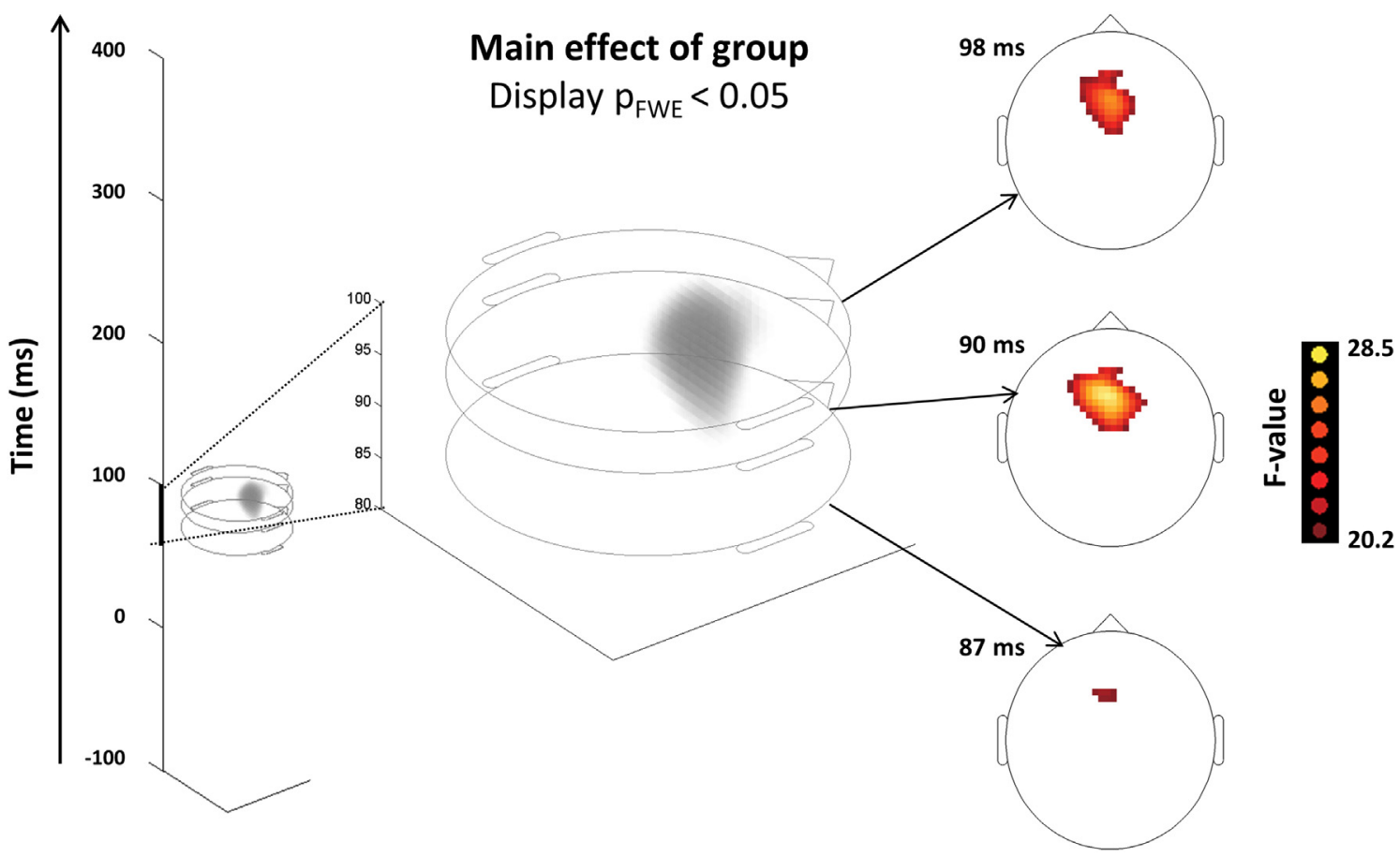

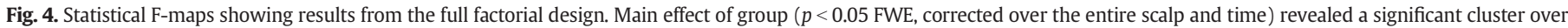
fronto-central channels peaking at $90 \mathrm{~ms}$.

at the cluster level) in the fronto-central areas. This effect was driven by a more negative $\mathrm{N} 1$ component in the 22q11.2 deletion carriers and confirms, in a statistically unbiased manner, the qualitative observation done in Fig. 3C-D. This finding suggests that carriers have greater sensitivity to tones in general (not specific to deviants) compared to controls. No main effect of condition or group by condition interaction effect was observed at the reported corrected threshold.

Post hoc tests assessing a potential effect of diagnosis showed no effect of diagnosis and the group effect persisted when controlling for diagnosis.

\section{3. $D C M$}

The family of DCMs with both forward and backward as well as lateral connections linking bilateral STG had the greatest exceedance probability (Fig. 5). BMA within the family with the highest exceedance probability showed that the intrinsic connection within right $\mathrm{A} 1$ was reduced in 22q11.2 relative to controls ( $\mathrm{F}_{1,41}=5.443, p=0.025$, uncorrected). This finding suggests decreased adaptation within right A1 for carriers than controls. In addition, we found reduced extrinsic connection from right IFG to STG $\left(\mathrm{F}_{1,41}=4.280, p=0.045\right.$, uncorrected $)$ in the carriers compared to controls, which suggests a disruption of top-down, or predictive processes in the 22q11.2. No effect of age was observed in either connection $\left(\mathrm{F}_{1,41}=0.012, p=0.915\right.$ for intrinsic connection, $\mathrm{F}_{1,41}<0.001, p=$ 0.984 for backward connection). We did not find an effect of sex on the intrinsic connection $\left(\mathrm{F}_{1,41}=0.263, p=0.811\right)$. However, we found that males had a reduced modulation of the backward connection $\left(\mathrm{F}_{1,41}=\right.$ 4.396, $p=0.042$ ) compared to females across the two groups. While the findings of reduced intrinsic connectivity within A1 and reduced top-down connectivity from IFG to STG are suggestive, they did not survive correction for multiple comparisons using a conservative Bonferroni correction for 12 tests. Running Bayesian model comparison separately in each group gave the following exceedance probabilities for the four families (controls: 0.16, 0.16 0.27, 0.41, 22q11.2DS: 0.14, 0.14, 0.07, 0.65). Hence, the family with the highest exceedance probability is consistent in both groups. Post hoc tests assessing a potential effect of diagnosis showed no effect of diagnosis and the group effect persisted when controlling for diagnosis. Results from the post hoc correlation for the effect of IQ and hearing levels within the 22q11.2DS group showed no correlation with hearing levels for any of the results. Correlation with IQ showed a correlation with the MMN amplitudes at the scalp level, see supplementary material for details.

\section{Discussion}

In this study, we investigated the responses elicited by a roving auditory MMN paradigm in a group of young 22q11.2 deletion carriers.

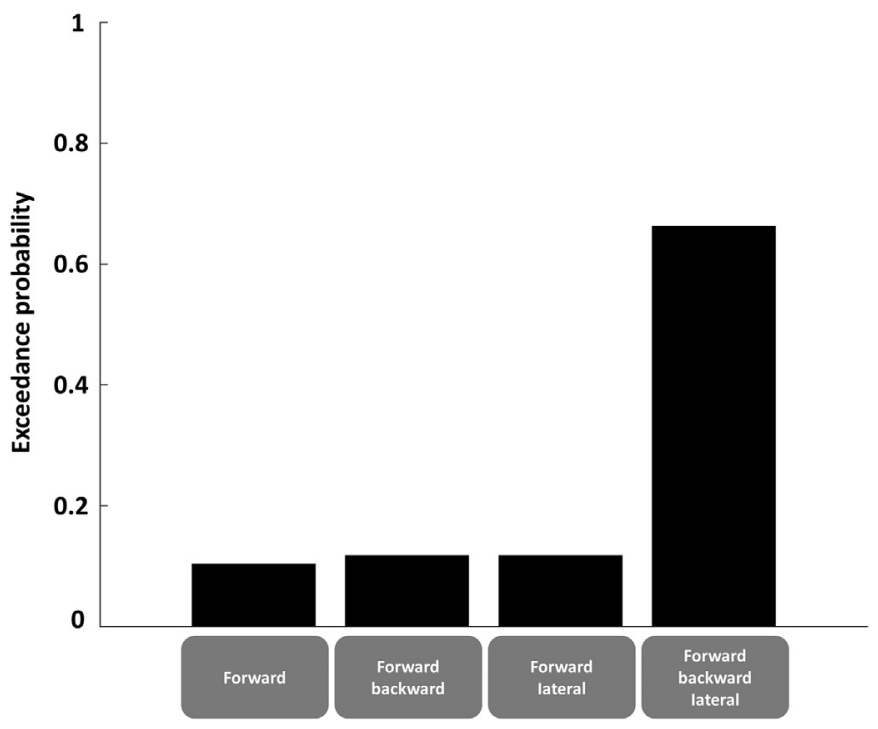

Fig. 5. Model exceedance probabilities for the four families. Forward; comprising models with forward connections, forward backward; models with forward and backward connections, Forward lateral; models with forward connections and lateral connections between bilateral STG. Forward backward lateral; models with forward and backward connections and lateral connections between bilateral STG The sum of the exceedance probabilities equals one. The family including models with forward, backward and lateral connections has the highest exceedance probability. 
While we found no indication of group differences between the MMN responses per se, the spatiotemporal analysis of responses to tones (standards and deviants) revealed a main effect of group in the frontocentral areas peaking at $90 \mathrm{~ms}$. This group difference was due to the 22q11.2 deletion carriers exhibiting larger negative responses in the N1 component, which suggests that 22q11.2 deletion carriers have greater sensitivity to tones. The dynamic interactions of the network structures underlying MMN were investigated with DCM and pointed to effective connectivity reductions in the backward, top-down, connection linking right IFG and STG, as well as the intrinsic connection within right A1. The reduction in top-down connectivity is indicative of a disruption in predictive processes in 22q11.2, and the reduced modulation within right $\mathrm{A} 1$ suggests decreased adaptation or impaired repetition suppression, that is, a failure to suppress neuronal responses to repeated stimuli (Auksztulewicz and Friston, 2016; Baldeweg, 2007; Garrido et al., 2009b).

The fact that the 22q11.2 deletion carriers in the present study showed a mismatch negativity response at the scalp level suggests that the change detection system is still functioning in this group. As reported in previous studies (Baker et al., 2005; Zarchi et al., 2013), we have also failed to show significant differences in the amplitude of frequency MMN between 22q11.2DS and controls. However, Baker et al. (2005) found reduced duration MMN in a 22q11.2 group which suggests that the system for generating MMN responses in 22q11.2 can be activated but is not functioning optimally. Further, it is possible that 22q11.2 show reduced MMN responses to duration deviants, but not frequency deviants. However, this would have to be confirmed in a future study to examine both in the same population.

We found group differences in the responses to tones at frontocentral electrodes at $90 \mathrm{~ms}$, the timing of the typical $\mathrm{N} 1$ component. The effect was driven by responses being greater (more negative) for $22 \mathrm{q} 11.2$ deletion carriers than controls and suggests that 22q11.2 deletion carriers are more sensitive to sounds. This is in line with Rihs et al. (2013) who also found in a 22q11.2 cohort an enhanced N1 component that was explained by a greater activation in the medial frontal cortex and the dorsal anterior cingulate. The N1 component has previously been found to be reduced in schizophrenia, as well as in first episode and first-degree relatives (Foxe et al., 2011; Umbricht et al., 2003). However, several studies have also failed to show this reduction, see (Rosburg et al., 2008) for a review. Different factors such as inter stimulus interval, medication and attention set are known to critically affect N1 (Rosburg et al., 2008) which could explain the inconsistency of N1 findings in schizophrenia.

DCM modelling of the difference between deviants and standards pointed towards reduced effective connectivity in the backward connection from IFG to STG in the right hemisphere as well as in the intrinsic connection within the right A1 for the 22q11.2DS compared to controls. Critically, disruptions within these same two connections have been previously found in patients with schizophrenia (Dima et al., 2012). Contrary to our study, however, Dima et al., 2012 found a stronger (not weaker) modulation of the backward connection from right IFG to right STG in the schizophrenia group. According to theoretical accounts of predictive coding, the forward or bottom-up connections convey information about the incoming stimuli and how well it matches expectations based on a learnt context (Friston, 2003). Expectations or predictions, on the other hand, are conveyed by top-down or backward connections. In light of this theory and evidence for reduced backward connectivity in 22q11DS, we speculate that controls are able to send down predictions indicated by the positive modulation from right IFG to right STG in a more efficient manner than the carriers. The reduced intrinsic connection within right A1 suggests that 22q11.2 deletion carriers exhibit less adaptation to the stimuli. While the scalp level data showed enhanced responses at the N1, it did not reveal an interaction between group and condition (standard and deviant). Therefore, it remains unclear whether increased responses to tones in 22q11DS is due to a boosted sensitivity to sounds in general or poorer adaptation to repeated sounds (i.e., impaired repetition suppression).
While the findings of reduced top-down effective connectivity from right frontal to temporal regions as well as reduced intrinsic connectivity within right A1 are interesting and suggestive, these results did not survive correction for multiple comparison. This together with the relatively small sample size of the study, suggest that findings should be considered preliminary. Replication in a larger study is needed before any strong conclusions can be drawn. Further, a proportion of the 22q11.2 deletion carriers included in the present study were presented with a diagnosis of either depression, anxiety or phobia, ASD, ADHD/ ADD. However, our post-hos test in the spatio-temporal as well as DCM analysis showed that the results could not be explained by the presence of a diagnosis.

The included 22q11.2 deletion carriers were young and nonpsychotic with a mean age of 15.5 years of age, i.e. before the median onset of schizophrenia. This could potentially be a limiting factor for finding strong effects. However, this age range was chosen since the focus was to look for premorbid phenotypes of psychosis. Further, this opens up for the possibility to study these deletion carriers longitudinally from before a mental disorder sets in.

In summary, we demonstrate that young non-psychotic 22q11.2 deletion carriers show enhanced responses to repeated stimuli, which might be due to either increased auditory sensitivity or reduced adaptation within the auditory cortex. In addition, we suggest a reduced ability to pass down predictions in cortical hierarchies. While the findings in the present study are promising and exciting, further work is required to corroborate the idea that reduced effective connectivity disruptions and enhanced $\mathrm{N} 1$ can be used as potential biomarkers, potentially in a follow-up longitudinal study.

\section{Contribution}

All authors contributed in the design of the study. KML and MRB collected the data. KML analysed the data and wrote the first draft of the manuscript. AV, HS and LO recruited the subjects and administered clinical assessment. All authors contributed to the interpretation of the data, revised the manuscript and agreed with the final content of the manuscript.

\section{Funding}

This study was funded by the Lundbeck Foundation, Denmark (R155-2014-1724); Lundbeck Foundation [Grant of Excellence "ContAct" R59 A5399]; Lundbeck Foundation fellowship (R105-9813); The Capital Region's Research Foundation for Mental Health Research.

\section{Conflict of interest}

H.R.S. received honoraria as speaker from Lundbeck A/S, Valby, Denmark, Biogen Idec, Denmark A/S, Genzyme, Denmark and MerckSerono, Denmark, honoraria as editor from Elsevier Publishers, Amsterdam, The Netherlands and Springer Publishing, Stuttgart, Germany, travel support from MagVenture, Denmark, and grant support from Biogen Idec, Denmark A/S. M.R.B is a prior employee at H. Lundbeck A/S, Denmark and received financial support for her PhD from the Innovation Fund Denmark. M.D. is employed with Lundbeck A/S. The authors declare no further biomedical financial interests or potential conflicts of interest.

This article is distributed under the Danish legislation governed by the Privacy Act (act\# 429, 31/05/2000), which does not permit data sharing at publicly available repositories or in raw formats. Summary statistics can be obtained through contact with the corresponding author (melissal@drcmr.dk).

\section{Acknowledgements}

We would like to thank all the participants and their families for taking the time to participate in this study and the Danish National 22q11DS Association for their strong support of our work. We would also like to express our gratitude to the staff involved in the Danish Blood Donor Study, Capital Region Blood bank, Glostrup. Further, we would like to thank http://www.forsogsperson.dk from which some of our control participants were recruited from. M.I.G acknowledges support from any Australian Research Council Discovery Early Career Researcher Award (DE130101393) and a University of Queensland Fellowship (2016000071). 


\section{Appendix A. Supplementary data}

Supplementary data to this article can be found online at https://doi. org/10.1016/j.schres.2018.01.026.

\section{References}

Adams, R.A., Stephan, K.E., Brown, H.R., Frith, C.D., Friston, K.J., 2013. The computational anatomy of psychosis. Front. Psychiatry 4:47. https://doi.org/10.3389/ fpsyt.2013.00047.

Atkinson, R.J., Michie, P.T., Schall, U., 2012. Duration mismatch negativity and P3a in firstepisode psychosis and individuals at ultra-high risk of psychosis. Biol. Psychiatry 71: 98-104. https://doi.org/10.1016/j.biopsych.2011.08.023.

Auksztulewicz, R., Friston, K., 2016. Repetition suppression and its contextual determinants in predictive coding. Cortex 80:125-140. https://doi.org/10.1016/j. cortex.2015.11.024

Baker, K., Baldeweg, T., Sivagnanasundaram, S., Scambler, P., Skuse, D., 2005. COMT Val108/158Met modifies mismatch negativity and cognitive function in 22q11 deletion syndrome. Biol. Psychiatry 58:23-31. https://doi.org/10.1016/j. biopsych.2005.03.020.

Baldeweg, T., 2007. ERP repetition effects and mismatch negativity generation: a predictive coding perspective. J. Psychophysiol. 21:204-213. https://doi.org/10.1027/02698803.21.34.204.

Baldeweg, T., Klugman, A., Gruzelier, J.H., Hirsch, S.R., 2002. Impairment in frontal but not temporal components of mismatch negativity in schizophrenia. Int. J. Psychophysiol. $43,111-122$

Bassett, A.S., Marshall, C.R., Lionel, A.C., Chow, E.W.C., Scherer, S.W., 2008. Copy number variations and risk for schizophrenia in 22q11.2 deletion syndrome. Hum. Mol. Genet. 17:4045-4053. https://doi.org/10.1093/hmg/ddn307.

Bodatsch, M., Brockhaus-Dumke, A., Klosterkötter, J., Ruhrmann, S., 2015. Forecasting psychosis by event-related potentials-systematic review and specific meta-analysis. Biol. Psychiatry 77:951-958. https://doi.org/10.1016/j.biopsych.2014.09.025.

Boly, M., Garrido, M.I., Gosseries, O., Bruno, M.-A., Boveroux, P., Schnakers, C., Massimini, M., Litvak, V., Laureys, S., Friston, K., 2011. Preserved Feedforward But Impaired TopDown Processes in the Vegetative State. Science 332 (6031):858-862. https://doi. org/10.1126/science.1202043.

Catts, S.V., Shelley, A.M., Ward, P.B., Liebert, B., McConaghy, N., Andrews, S., Michie, P.T. 1995. Brain potential evidence for an auditory sensory memory deficit in schizophrenia. Am. J. Psychiatry 152:213-219. https://doi.org/10.1176/ajp.152.2.213.

David, O., Kiebel, S.J., Harrison, L.M., Mattout, J., Kilner, J.M., Friston, K.J., 2006. Dynamic causal modeling of evoked responses in EEG and MEG. NeuroImage 30:1255-1272. https://doi.org/10.1016/j.neuroimage.2005.10.045.

Delorme, A., Makeig, S., 2004. EEGLAB: an open source toolbox for analysis of single-trial EEG dynamics including independent component analysis. J. Neurosci. Methods 134: 9-21. https://doi.org/10.1016/j.jneumeth.2003.10.009.

Dima, D., Dietrich, D.E., Dillo, W., Emrich, H.M., 2010. Impaired top-down processes in schizophrenia: a DCM study of ERPs. Neurolmage 52:824-832. https://doi.org/ 10.1016/j.neuroimage.2009.12.086.

Dima, D., Frangou, S., Burge, L., Braeutigam, S., James, A.C., 2012. Abnormal intrinsic and extrinsic connectivity within the magnetic mismatch negativity brain network in schizophrenia: a preliminary study. Schizophr. Res. 135:23-27. https://doi.org/ 10.1016/j.schres.2011.12.024

Doeller, C.F.C., Opitz, B., Mecklinger, A., Krick, C., Reith, W., Schröger, E., 2003. Prefrontal cortex involvement in preattentive auditory deviance detection: neuroimaging and electrophysiological evidence. Neurolmage 20:1270-1282. https://doi.org/10.1016/ S1053-8119(03)00389-6.

Fogelson, N., Litvak, V., Peled, A., Fernandez-del-Olmo, M., Friston, K., 2014. The functional anatomy of schizophrenia: a dynamic causal modeling study of predictive coding. Schizophr. Res. 158:204-212. https://doi.org/10.1016/j.schres.2014.06.011.

Foxe, J.J., Yeap, S., Snyder, A.C., Kelly, S.P., Thakore, J.H., Molholm, S., 2011. The N1 auditory evoked potential component as an endophenotype for schizophrenia: high-density electrical mapping in clinically unaffected first-degree relatives, first-episode, and chronic schizophrenia patients. Eur. Arch. Psychiatry Clin. Neurosci. 261:331-339. https://doi.org/10.1007/s00406-010-0176-0.

Friston, K.J., 1998. The disconnection hypothesis. Schizophr. Res. 30:115-125. https://doi. org/10.1016/S0920-9964(97)00140-0.

Friston, K., 2003. Learning and inference in the brain. Neural Netw. 16, 1325-1352.

Friston, K.J., Harrison, L., Penny, W., 2003. Dynamic causal modelling. Neurolmage 19: 1273-1302. https://doi.org/10.1016/S1053-8119(03)00202-7.

Garrido, M.I., Kilner, J.M., Kiebel, S.J., Friston, K.J., 2007. Evoked brain responses are generated by feedback loops. Proc. Natl. Acad. Sci. U. S. A. 104:20961-20966. https://doi. org/10.1073/pnas.0706274105.

Garrido, M.I., Friston, K.J., Kiebel, S.J., Stephan, K.E., Baldeweg, T., Kilner, J.M., 2008. The functional anatomy of the MMN: a DCM study of the roving paradigm. Neurolmage 42:936-944. https://doi.org/10.1016/j.neuroimage.2008.05.018.

Garrido, M.I., Kilner, J., Kiebel, S., Friston, K., 2009a. Dynamic causal modeling of the response to frequency deviants. J. Neurophysiol. 101:2620-2631. https://doi.org/ 10.1152/jn.90291.2008.

Garrido, M.I., Kilner, J.M., Kiebel, S.J., Stephan, K.E., Friston, K.J., 2009b. Repetition suppression and plasticity in the human brain. Neurolmage 48, 269-279 doi:10.1016/j. neuroimage.2009.06.034.Repetition.

Goodship, J., Cross, I., LiLing, J., Wren, C., 1998. A population study of chromosome 22q11 deletions in infancy. Arch. Dis. Child. 79, 348-351.
Grau, C., Fuentemilla, L., Marco-Pallares, J., 2007. Functional neural dynamics underlying auditory event-related N1 and N1 suppression response. NeuroImage 36, 522-531

Hoeffding, L.K., Trabjerg, B.B., Olsen, L., Mazin, W., Sparsø, T., Vangkilde, A., Mortensen, P.B., Pedersen, C.B., Werge, T., 2017. Risk of psychiatric disorders among individuals with the 22q11.2 deletion or duplication. JAMA Psychiat. 74:282. https://doi.org/ 10.1001/jamapsychiatry.2016.3939.

Hsieh, M.H., Shan, J.-C., Huang, W.-L., Cheng, W.-C., Chiu, M.-J., Jaw, F.-S., Hwu, H.-G., Liu, C.-C., 2012. Auditory event-related potential of subjects with suspected pre-psychotic state and first-episode psychosis. Schizophr. Res. 140:243-249. https://doi.org/ 10.1016/j.schres.2012.06.021.

Jessen, F., Fries, T., Kucharski, C., Nishimura, T., Hoenig, K., Maier, W., Falkai, P., Heun, R. 2001. Amplitude reduction of the mismatch negativity in first-degree relatives of patients with schizophrenia. Neurosci. Lett. https://doi.org/10.1016/S0304-3940(01) 02072-9.

Jiramongkolchai, P., Kumar, M.S., Chinnadurai, S., Wootten, C.T., Goudy, S.L., 2016. Prevalence of hearing loss in children with 22q11.2 deletion syndrome. Int. J. Pediatr Otorhinolaryngol. 87:130-133. https://doi.org/10.1016/j.ijporl.2016.06.005.

Karayiorgou, M., Simon, T.J., Gogos, J.A., 2010. 22q11.2 microdeletions: linking DNA structural variation to brain dysfunction and schizophrenia. Nat. Rev. Neurosci. 11: 402-416. https://doi.org/10.1038/nrn2841.

Kilner, J., Friston, K., 2010. Topological inference for EEG and MEG. Ann. Appl. Stat. 4 $1272-1290$

Marshall, C.R., Howrigan, D.P., Merico, D., Thiruvahindrapuram, B., Wu, W., Greer, D.S. Antaki, D., Shetty, A., Holmans, P.A., Pinto, D., Gujral, M., Brandler, W.M., Malhotra, D. Wang Z, Fajarado, K.V.F., Maile, M.S, Ripke, S., Agartz, I, Albus, M., Alexander, M., Amin, F., Atkins, J., Bacanu, S.A., Belliveau, R.A., Bergen, S.E., Bertalan, M., Bevilacqua, E., Bigdeli, T.B., Black, D.W., Bruggeman, R., Buccola, N.G., Buckner, R.L. Bulik-Sullivan, B., Byerley, W., Cahn, W., Cai, G., Cairns, M.J., Campion, D., Cantor, R.M., Carr, V.J., Carrera, N., Catts, S.V., Chambert, K.D., Cheng, W., Cloninger, C.R. Cohen, D., Cormican, P., Craddock, N., Crespo-Facorro, B., Crowley, J.J., Curtis, D. Davidson, M., Davis, K.L., Degenhardt, F., Del Favero, J., DeLisi, L.E., Dikeos, D., Dinan, T. Djurovic, S., Donohoe, G., Drapeau, E., Duan, J., Dudbridge, F., Eichhammer, P. Eriksson, J., Escott-Price, V., Essioux, L., Fanous, A.H., Farh, K.-H., Farrell, M.S., Frank J., Franke, L., Freedman, R., Freimer, N.B., Friedman, J.I., Forstner, A.J., Fromer, M., Genovese, G., Georgieva, L., Gershon, E.S., Giegling, I., Giusti-Rodríguez, P., Godard, S., Goldstein, J.I., Gratten, J., de Haan, L., Hamshere, M.L., Hansen, M., Hansen, T., Haroutunian, V., Hartmann, A.M., Henskens, F.A., Herms, S., Hirschhorn, J.N., Hoffmann, P., Hofman, A., Huang, H., Ikeda, M., Joa, I., Kähler, A.K., Kahn, R.S. Kalaydjieva, L., Karjalainen, J., Kavanagh, D., Keller, M.C., Kelly, B.J., Kennedy, J.L, Kim, Y., Knowles, J.A., Konte, B., Laurent, C., Lee, P., Lee, S.H., Legge, S.E., Lerer, B. Levy, D.L., Liang, K.-Y., Lieberman, J., Lönnqvist, J., Loughland, C.M., Magnusson, P.K.E., Maher, B.S., Maier, W., Mallet, J., Mattheisen, M., Mattingsdal, M., McCarley, R.W., McDonald, C., McIntosh, A.M., Meier, S., Meijer, C.J., Melle, I., MesholamGately, R.I., Metspalu, A., Michie, P.T., Milani, L., Milanova, V., Mokrab, Y., Morris, D.W., Müller-Myhsok, B., Murphy, K.C., Murray, R.M., Myin-Germeys, I., Nenadic, I., Nertney, D.A, Nestadt, G, Nicodemus, K.K. Nisenbaum, L, Nordin, A O'Callaghan, E., O'Dushlaine, C., Oh, S.-Y., Olincy, A., Olsen, L., O'Neill, F.A., Van Os, J., Pantelis, C., Papadimitriou, G.N., Parkhomenko, E., Pato, M.T., Paunio, T., Perkins, D.O., Pers, T.H., Pietiläinen, O., Pimm, J., Pocklington, A.J., Powell, J., Price, A., Pulver, A.E., Purcell, S.M., Quested, D., Rasmussen, H.B., Reichenberg, A., Reimers, M.A., Richards, A.L Roffman, J.L., Roussos, P., Ruderfer, D.M., Salomaa, V., Sanders, A.R., Savitz, A., Schall, U., Schulze, T.G., Schwab, S.G., Scolnick, E.M., Scott, R.J., Seidman, L.J., Shi, J., Silverman, J.M., Smoller, J.W., Söderman, E., Spencer, C.C.A., Stahl, E.A., Strengman, E., Strohmaier, J., Stroup, T.S., Suvisaari, J., Svrakic, D.M., Szatkiewicz, J.P., Thirumalai, S., Tooney, P.A., Veijola, J., Visscher, P.M., Waddington, J., Walsh, D., Webb, B.T. Weiser, M., Wildenauer, D.B., Williams, N.M., Williams, S., Witt, S.H., Wolen, A.R. Wormley, B.K., Wray, N.R., Wu, J.Q., Zai, C.C., Adolfsson, R., Andreassen, O.A Blackwood, D.H.R., Bramon, E., Buxbaum, J.D., Cichon, S., Collier, D.A., Corvin, A. Daly, M.J., Darvasi, A., Domenici, E., Esko, T., Gejman, P.V., Gill, M., Gurling, H. Hultman, C.M., Iwata, N., Jablensky, A.V., Jönsson, E.G., Kendler, K.S., Kirov, G., Knight, J., Levinson, D.F., Li, Q.S., McCarroll, S.A., McQuillin, A., Moran, J.L., Mowry, B.J., Nöthen, M.M., Ophoff, R.A., Owen, M.J., Palotie, A., Pato, C.N., Petryshen, T.L., Posthuma, D., Rietschel, M., Riley, B.P., Rujescu, D., Sklar, P., St Clair, D., Walters, J.T.R., Werge, T., Sullivan, P.F., O'Donovan, M.C., Scherer, S.W., Neale, B.M., Sebat, J., 2016. Contribution of copy number variants to schizophrenia from a genome-wide study of 41,321 subjects. Nat. Genet. 49:27-35. https://doi.org/10.1038/ng.3725.

McGlashan, T.H., Miller, T.J., Woods, S.W., Rosen, J.L., Hoffmann, R.E., Davidson, L., 2012 Structured Interview for Prodromal Syndromes (SIPS). Norsk Version 5.0. Stavanger Universitetssjukehus, Norge.

Michie, P.T., 2001. What has MMN revealed about the auditory system in schizophrenia? Int. J. Psychophysiol. 42:177-194. https://doi.org/10.1016/S0167-8760(01)00166-0.

Michie, P.T., Innes-Brown, H., Todd, J., Jablensky, A.V., 2002. Duration mismatch negativity in biological relatives of patients with schizophrenia spectrum disorders. Biol. Psychiatry 52:749-758. https://doi.org/10.1016/S0006-3223(02)01379-3.

Miller, T.J., McGlashan, T.H., Rosen, J.L., Cadenhead, K., Cannon, T., Ventura, J., McFarlane, W., Perkins, D.O., Pearlson, G.D., Woods, S.W., 2003. Prodromal assessment with the structured interview for prodromal syndromes and the scale of prodromal symptoms: predictive validity, interrater reliability, and training to reliability. Schizophr. Bull. 29, 703-715.

Näätänen, R., 1995. The mismatch negativity. Ear Hear. 16:6-18. https://doi.org/10.1097/ 00003446-199502000-00002.

Näätänen, R., Kähkönen, S., 2009. Central auditory dysfunction in schizophrenia as revealed by the mismatch negativity (MMN) and its magnetic equivalent MMNm: a review. Int. J. Neuropsychopharmacol. 12:125-135. https://doi.org/10.1017/ S1461145708009322. 
Näätänen, R., Paavilainen, P., Rinne, T., Alho, K., 2007. The mismatch negativity (MMN) in basic research of central auditory processing: a review. Clin. Neurophysiol. 118: 2544-2590. https://doi.org/10.1016/j.clinph.2007.04.026.

Opitz, B., Rinne, T., Mecklinger, A., von Cramon, D.Y., Schröger, E., 2002. Differential contribution of frontal and temporal cortices to auditory change detection: fMRI and ERP results. NeuroImage 15:167-174. https://doi.org/10.1006/nimg.2001.0970.

Oskarsdóttir, S., Vujic, M., Fasth, A., 2004. Incidence and prevalence of the 22q11 deletion syndrome: a population-based study in Western Sweden. Arch. Dis. Child. 89, 148-151.

Penny, W.D., Stephan, K.E., Daunizeau, J., Rosa, M.J., Friston, K.J., Schofield, T.M., Leff, A.P., 2010. Comparing families of dynamic causal models. PLoS Comput. Biol. 6, e1000709. https://doi.org/10.1371/journal.pcbi.1000709.

Purcell, S.M., Wray, N.R., Stone, J.L., Visscher, P.M., O'Donovan, M.C., Sullivan, P.F., Sklar, P., 2009. Common polygenic variation contributes to risk of schizophrenia and bipolar disorder. Nature 460:748-752. https://doi.org/10.1038/nature08185.

Randeniya, R., Oestreich, L.K.L., Garrido, M.I., 2017. Sensory prediction errors in the continuum of psychosis. Schizophr. Res. https://doi.org/10.1016/j.schres.2017.04.019.

Ranlund, S., Adams, R.A., Díez, A., Constante, M., Dutt, A., Hall, M.-H., Maestro Carbayo, A McDonald, C., Petrella, S., Schulze, K., Shaikh, M., Walshe, M., Friston, K., Pinotsis, D., Bramon, E., 2016. Impaired prefrontal synaptic gain in people with psychosis and their relatives during the mismatch negativity. Hum. Brain Mapp. 37:351-365. https://doi.org/10.1002/hbm.23035.

Rao, R.P., Ballard, D.H., 1999. Predictive coding in the visual cortex: a functional interpretation of some extra-classical receptive-field effects. Nat. Neurosci. 2:79-87. https:// doi.org/10.1038/4580.

Reynolds, C.R., Kamphaus, R.W., 2011. Reynolds Intellectual Assessment Scales (RIAS) Reynolds Intellectual Screening Test (RIST). Dansk version - Vejledning. Hogrefe Psykologisk Forlag, København, Danmark.

Rihs, T. A. Tomescu, M.I Britz, J., Rochas, V., Custo, A Schneider, M., Debbané, M., Eliez, S Michel, C.M., 2013. Altered auditory processing in frontal and left temporal cortex in 22q11.2 deletion syndrome: a group at high genetic risk for schizophrenia. Psychiatry Res. 212:141-149. https://doi.org/10.1016/j.pscychresns.2012.09.002.

Rinne, T., Alho, K., Ilmoniemi, R., Virtanen, J., Näätänen, R., 2000. Separate time behaviors of the temporal and frontal mismatch negativity sources. Neurolmage 12, 14-19.

Robin, N.H., Shprintzen, R.J., 2005. Defining the clinical spectrum of deletion 22q11.2. J. Pediatr. 147:90-96. https://doi.org/10.1016/j.jpeds.2005.03.007.

Rosburg, T., Boutros, N.N., Ford, J.M., 2008. Reduced auditory evoked potential component N100 in schizophrenia-a critical review. Psychiatry Res. 161:259-274. https://doi. org/10.1016/j.psychres.2008.03.017.

Schmock, H., Vangkilde, A., Larsen, K.M., et al., 2015. The Danish 22q11 research initiative. BMC Psychiatry 15, 220

Schneider, M., Debbané, M., Bassett, A.S., Chow, E.W.C., Fung, W.L.A., van den Bree, M., et al., 2014. Psychiatric disorders from childhood to adulthood in 22q11.2 deletion syndrome: results from the international consortium on brain and behavior in 22q11.2 deletion syndrome. Am. J. Psychiatry 171:627-639. https://doi.org/ 10.1176/appi.ajp.2013.13070864

Shprintzen, Robert J., 2005. In: Cassidy, S., Allanson, J.E. (Eds.), Management of Genetic Syndromes. J. Wiley, New York, Hoboken, N.J., pp. 615-632.

Stefansson, H., Rujescu, D., Cichon, S., 2008. Large recurrent microdeletions associated with schizophrenia. Nature 455, 232-236.

Szatkiewicz J.P. O'Dushlaine, C Chen, G., Chambert, K, Moran, J.L, Neale, B.M. Fromer, M., Ruderfer, D., Akterin, S., Bergen, S.E., Kähler, A., Magnusson, P.K.E., Kim, Y., Crowley, J.J., Rees, E., Kirov, G., O'Donovan, M.C., Owen, M.J., Walters, J., Scolnick, E., Sklar, P., Purcell, S., Hultman, C.M., McCarroll, S.A., Sullivan, P.F., 2014. Copy number variation in schizophrenia in Sweden. Mol. Psychiatry 19:762-773. https://doi.org/ 10.1038/mp.2014.40.

Umbricht, D., Krljesb, S., 2005. Mismatch negativity in schizophrenia: a meta-analysis. Schizophr. Res. 76:1-23. https://doi.org/10.1016/j.schres.2004.12.002.

Umbricht, D. Koller, R, Schmid, L, Skrabo, A Grübel, C, Huber, T, Stassen, H., 2003. How specific are deficits in mismatch negativity generation to schizophrenia? Biol. Psychiatry $53,1120-1131$

Vangkilde, A., Jepsen, J.R.M., Schmock, H., Olesen, C., Arnarsdóttir, S., Baaré, W.F.C., Plessen, K.J., Didriksen, M., Siebner, H.R., Werge, T., Olsen, L., 2016a. Associations between social cognition, skills, and function and subclinical negative and positive symptoms in 22q11.2 deletion syndrome. J. Neurodev. Disord. 8:42. https://doi.org/10.1186/ s11689-016-9175-4.

Vangkilde, A., Olsen, L., Hoeffding, L.K., Pedersen, C.B., Mortensen, P.B., Werge, T., Trabjerg, B, 2016b. Schizophrenia spectrum disorders in a Danish 22q11.2 deletion syndrome cohort compared to the total Danish population-a nationwide register study. Schizophr. Bull. 42:824-831. https://doi.org/10.1093/schbul/sbv195.

Vorstman, J.A.S., Breetvelt, E.J., Duijff, S.N., Eliez, S., Schneider, M., Jalbrzikowski, M., Armando, M., Vicari, S., Shashi, V., Hooper, S.R., Chow, E.W.C., Fung, W.L.A., Butcher, N.J., Young, D.A., McDonald-McGinn, D.M., Vogels, A., van Amelsvoort, T., Gothelf, D., Weinberger, R., Weizman, A., Klaassen, P.W.J., Koops, S., Kates, W.R., Antshel, K.M., Simon, T.J., Ousley, O.Y., Swillen, A., Gur, R.E., Bearden, C.E., Kahn, R.S., Bassett, A.S., 2015. International consortium on brain and behavior in 22q11.2 deletion syndrome, I. 22q11. B.B.S., 2015. Cognitive decline preceding the onset of psychosis in patients with 22q11.2 deletion syndrome. JAMA Psychiatry 72:377-385. https://doi. org/10.1001/jamapsychiatry.2014.2671.

Zarchi, O., Carmel, M., Avni, C., Attias, J., Frisch, A., Michaelovsky, E., Patya, M., Green, T., Weinberger, R., Weizman, A., Gothelf, D., 2013. Schizophrenia-like neurophysiological abnormalities in 22q11.2 deletion syndrome and their association to COMT and PRODH genotypes. J. Psychiatr. Res. 47:1623-1629. https://doi.org/10.1016/j. jpsychires.2013.07.004. 